\title{
ARQUIVOS DE NEURO-PSIQUIATRIA NA DÉCADA DO CÉREBRO
}

Com este Número, atinge-se o início da publicação do Volume 50 de ARQUIVOS DE NEURO-PSIQUIATRIA, dentro da absoluta regularidade trimestral mantida desde o Volume 1 Número 1 (1943) até agora, feito raro senão inédito na literatura médica especializada latino-americana. Assim como dessa regularidade se orgulhava o Dr. Oswaldo Lange - seu fundador, êmulo e editor até 1986 - também se orgulham seus continuadores que, em equipe, dela cuidam mediante o trabalho continuado desenvolvido na Associação Arquivos de Neuro-Psiquiatria Dr. Oswaldo Lange.

Além da regularidade, tem caracterizado ARQUIVOS DE NEURO-PSIQUIATRIA a qualidade do seu conteúdo, o qual abrange o melhor do que cientificamente se produz no Brasil em neurociências, particularmente em Neurologia. Para manter tal qualidade do conteúdo, muito têm dado de si os avaliadores ( $\ll$ referees») e, a cada um deles, a Associação agradece vivamente pelo eficiente desempenho.

Qualidade do conteúdo científico e regularidade da publicação encontram-se entre os motivos principais que mantêm a indexação internacional de ARQUIVOS DE NEURO-PSIQULATRIA, de tal forma a garantir aos artigos e aos seus autores os mesmos foros que prevalecem em relação às revistas publicadas em meios melhor aquinhoados. Nos dias de hoje, encontram-se entre estas últimas aqueles periódicos publicados em inglês no primeiro mundo. Nem sempre, porém, a catalogação e a indexação bastam por si só. Encontra a publicação científica oriunda de ambientes locados no mundo em desenvolvimento determinadas barreiras. Não compete discutir aqui suas causas, geralmente ditadas por limitantes de ordem econômica ou por incongruente competividade cientifica. Compete, isto sim, lembrar fatores de ordem local que devem ser avaliados frontalmente. Dois deles merecem destaque.

O primeiro é a falta de comunicação e de interconsulta adequadas, ou adequadamente mantidas, entre os publicadores e editores de periódicos científicos. Não é alimentado, assim, o espirito de colaboração entre eles, do qual, só poderiam resultar construtiva competitividade e útil troca de experiência. Com isto seria também alimentada a informação científica, tanto em plano nacional como internacional. necessário somar esforços e, não, dividí-los.

O segundo é o desinteresse por parte dos pesquisadores pelo que não é publicado em inglês e em revistas do primeiro mundo. Esta verdadeira doença científica, há muito registrada e veementemente criticada por Santiago Ramón y Cajal, se alastra de forma daninha entre nossos pesquisadores. Ao ignorar por exemplo o que se publica aqui no Brasil, abrem eles as comportas para que outros pesquisadores tomem atitude igualmente parca de responsabilidade. Resulta a situação de um não citar o outro e vice-versa, hoje tão frequentemente documentada. Sem priorizar, é necessário referir o que foi publicado no meio a que pertence o pesquisador. Será assegurada entre eles, assim, a troca de informação $\theta$ a comunicação, bem como a crítica do conteúdo científico - passo essencial para 
- progresso em pesquisa. essencial ao pesquisador a auto-avaliação e esta se amplia à medida em que avalia o resultado de pesquisas de outros. assim que de Discipulo se passa a Mestre. dessa forma que os Mestres construtivamente se interalimentam. por esse modo que se sedimentam as Escolas, as verdadeiras pelo menos.

ARQUIVOS DE NEURO-PSIQUIATRIA, como periódico, encontra-se aberto e pronto ao intercâmbio de comunicação e à interconsulta de informação, lembradas no primeiro exemplo. Para o segundo exemplo, aponta a necessidade de ampliar os horizontes cientificos da Neurologia aqui em nosso meio. Mantém e tem suas páginas abertas para cobrir essa necessidade universitária. Aqui, entenda-se universidade como polo magnético de cultura e não, simplesmente, instituição do sistema educacional vigente. Destas últimas o país não carece. Necessita, isto sim, de verdadeiros núcleos de cultivo da cultura. Em nosso caso brasileiro, raros são eles. ARQUIVOS DE NEURO-PSIQUIATRIA está pronto para dar sua contribuição ativa e continuada a tanto.

Assim, tomando em conta os exemplos analisados, as idéias e as contribuições de todos aqueles vinculados a ARQUIVOS DE NEURO-PSIQUIATRIA são benvindas, como convocado é o engajamento de todos ao real modo universitário de contribuir para o estudo e para a pesquisa em Neurologia. S6 assim estaremos todos, unidos, no panorama local deste decênio, contribuindo à Década do Cérebro - como proclamada pela Federação Mundial de Neurologia e assim aceita pela Academia Brasileira de Neurologia, da qual é porta-voz ARQUIVOS DE.NEUROPSIQUIATRIA. 